\title{
Carbides Evolution and Tensile Property of 4Cr5MoSiV1 Die Steel with Rare Earth Addition
}

\author{
Hanghang Liu 1,2, Paixian Fu 1,2,*, Hongwei Liu 1,2, Chen Sun 1,2, Jinzhu Gao ${ }^{1,2}$ \\ and Dianzhong $\mathrm{Li}^{1,2}$ \\ 1 Institute of Metal Research, Chinese Academy of Sciences, 72 Wenhua Road, Shenyang 110016, China; \\ hhliu15b@imr.ac.cn (H.L.); hwliu@imr.ac.cn (H.L.); csun15s@imr.ac.cn (C.S.); jzgao11b@imr.ac.cn (J.G.); \\ dzli@imr.ac.cn (D.L.) \\ 2 School of Materials Science and Engineering, University of Science and Technology of China, \\ 72 Wenhua Road, Shenyang 110016, China \\ * Correspondence: pxfu@imr.ac.cn; Tel.: +86-24-2397-1973
}

Received: 17 September 2017; Accepted: 13 October 2017; Published: 18 October 2017

\begin{abstract}
Studies of 4Cr5MoSiV1 die steel suggest that under appropriate conditions, additions of rare earth (RE) can enhance tensile property. This improvement is apparently due to the more uniform distribution of carbides and the enhancement of precipitation strengthening after RE additions. In this present work, the effect of the RE addition on the carbides evolution and tensile property of $4 \mathrm{Cr} 5 \mathrm{MoSiV} 1$ steel with various RE contents $(0,0.018,0.048$ and $0.15 \mathrm{wt} \%)$ were systematically investigated. The two-dimensional detection techniques such as optical microscopy (OM), scanning electron microscopy (SEM), transmission electron microscopy (TEM), and X-ray diffraction (XRD) were used to investigate the carbides evolution of as-cast, annealed and tempered with RE addition. The results indicated that the carbides in $4 \mathrm{Cr} 5 \mathrm{MoSiV} 1$ steels were modified by adding the suitable amount of RE. The eutectic structure and coarse eutectic carbides were all refining and the morphology of the annealed carbides initiated change from strip shape to ellipsoidal shape compared with the unmodified test steel (ORE). In addition, the amount of the tempered $\mathrm{M}_{8} \mathrm{C}_{7}$ carbides increased initially and then decreased with the alteration of RE addition from 0.018 to $0.15 \mathrm{wt} \%$. Notably, the tensile test indicated that the average value of ultimate tensile strength (UTS) and elongation rate of 0.048RE steel increased slightly to $1474 \mathrm{MPa}$ and $15 \%$, higher than the $1452 \mathrm{MPa}$ and $12 \%$ for the unmodified test steel (0RE), respectively. Such an addition of RE ( $0.048 \mathrm{wt} \%)$ would have a significant effect on the carbides evolution of as-cast, annealed and tempered and resulting in the tensile property of $4 \mathrm{Cr} 5 \mathrm{MoSiV} 1$ die steel.
\end{abstract}

Keywords: rare earth; 4Cr5MoSiV1 die steel; carbides evolution; tensile strength; elongation rate

\section{Introduction}

4Cr5MoSiV1 is an excellent hot-worked die steel, which is widely applied in fields such as hot forging, hot extrusion and die-casting. Usually, the working surface temperature of dies can get up to $550{ }^{\circ} \mathrm{C}$, which is very close to the tempering temperature of die steel. Continuous evolution of the microstructure will occur and significantly affect the various properties of the die steel [1]. Actually, the cracks as a network are normally observed on the die surface, which results in more than $80 \%$ failure of hot-work dies [2]. To date, researchers found that the uniform hardness, impact toughness, tensile strength and high temperature fatigue strength will be beneficial to prolong the service life when the die steel is subjected to intense friction and mechanical shock in service [3-9]. In addition, N. Mebarki [10], S. Kheirandish [11] and X. Hu [12] found that the coarse eutectic carbides in the process of thermal fatigue could decrease the cyclic softening behavior and lead to fatigue failure. Due to the segregation of chemical constituents, coarse eutectic carbides can be formed during solidification, which can promote crack growth and early failure, and should be reduced by appropriate methods. 
The effect of rare earth (RE) in steels is well known as a deoxidizer and desulphuriser. The size and morphology of non-metallic inclusions in steels have changed dramatically after adding $\mathrm{Ce}, \mathrm{La}$, Y and Ga [13-17]. Fu [18] and Gao [19] also reported that RE elements like Ce, La and Y can form highly stable oxides, oxy-sulphides and sulphides, which precipitate as solid particles in the melt due to their high melting temperatures. It was shown that the grain size of steel could be refined with a suitable amount of RE and resulted in enhanced impact toughness [16]. In addition, adding RE elements in steel also was an effective method to improve the hot ductility, corrosion properties and abrasion resistance [20-23]. However, there were only a few reports on the improvement of mechanical properties and related changes in carbides due to RE addition. It was shown that the morphology of eutectic carbides changed from network-like structures to granular carbides and resulted in improved mechanical properties in cast steel $[15,18,24,25]$. However, the influence of RE on the evolution of as-cast, annealed and tempered carbides in $4 \mathrm{Cr} 5 \mathrm{MoSiV} 1$ steel is still controversially discussed because of the lack of quantitative experimental data. In general, the reason for the enhancement of the tensile property points to morphological changes of the phase constituents and phase fractions [15].

In this study, the influence of RE additions $(0,0.018,0.048$ and $0.15 \mathrm{wt} \%)$ on the carbides evolution and tensile property of $4 \mathrm{Cr} 5 \mathrm{MoSiV} 1-\mathrm{RE}$ die steel were investigated. Intensive investigations were done regarding the changes of the microstructure constituents as well as the influence of the changing carbides phase fractions on the tensile property.

\section{Experimental Procedures}

The four experimental raw materials of $4 \mathrm{Cr} 5 \mathrm{MoSiV} 1$ steel were fabricated with $25 \mathrm{~kg}$ capacity medium frequency induction furnace, and the chemical compositions were shown in Table 1 . The RE (mainly containing $30 \mathrm{wt} \% \mathrm{La}$ and $70 \mathrm{wt} \% \mathrm{Ce}$ ) were added into the molten steel under the vacuum atmosphere when the oxygen content of the steel was reduced to a low level (lower than $10 \mathrm{ppm}$ ). Different amounts of RE were added into the melt, wrapped in pure iron foil, stirred to ensure the homogeneity of compositions. The residual amounts of RE in steel were $0,0.018,0.048$ and $0.15 \mathrm{wt}$ $\%$, respectively.

Table 1. Chemical composition of test steels (wt \%).

\begin{tabular}{ccccccccccccc}
\hline Alloy & C & Si & Mn & Cr & Mo & V & $\mathbf{P}$ & S & O & N & H & RE \\
\hline 0 rare earth (RE) & 0.37 & 1.18 & 0.50 & 5.00 & 1.42 & 1.05 & 0.005 & 0.005 & 0.0008 & 0.0045 & 1.7 & 0 \\
0.018RE & 0.35 & 1.20 & 0.48 & 4.90 & 1.40 & 1.04 & 0.005 & 0.003 & 0.0006 & 0.0044 & 1.3 & 0.018 \\
0.048RE & 0.35 & 1.18 & 0.52 & 5.00 & 1.39 & 1.04 & 0.003 & 0.003 & 0.0006 & 0.0046 & 1.0 & 0.048 \\
0.15RE & 0.36 & 1.20 & 0.50 & 4.92 & 1.40 & 1.05 & 0.003 & 0.003 & 0.0005 & 0.0045 & 0.8 & 0.15 \\
\hline
\end{tabular}

Four raw materials were homogenized at $1200^{\circ} \mathrm{C}$ for two hours, and hot-forged at the temperature ranging from $950^{\circ} \mathrm{C}$ to $1150{ }^{\circ} \mathrm{C}$. All the ingots were air-cooled down to room temperature after forging. The final size of forging ingots was $70 \mathrm{~mm} \times 70 \mathrm{~mm} \times 500 \mathrm{~mm}$. Subsequently, the heat treatment process of the four forged materials was carried out. Firstly, the samples were heated to $870{ }^{\circ} \mathrm{C}$ for two hours, then cooled to $740{ }^{\circ} \mathrm{C}$ and isothermal annealing for four hours, and eventually furnace-cooled to room temperature. Subsequently, the quenching and the two times high-temperature tempering process were performed at $600{ }^{\circ} \mathrm{C}$ and $610{ }^{\circ} \mathrm{C}$, respectively. The quenching needed to remain one hour at $1040{ }^{\circ} \mathrm{C}$, then was oil-cooled. The remaining time of tempering temperature was two hours, and then air-cooling was carried out.

After conventional metallographic preparation, polished surfaces were etched with $4 \%$ nital solution ( $4 \mathrm{~mL} \mathrm{HNO}_{3}, 96 \mathrm{~mL} \mathrm{C}_{2} \mathrm{H}_{5} \mathrm{OH}$ ) for subsequent optical microscopy (OM) (Leica Co, DM ILM, Wetzlar, Germany) and scanning electron microscopy (SEM) (JSM-6301F, Japan Electronics Corporation, Tokyo, Japan). Metallographic observations were carried out on the specimens' subjected to as-cast and annealed state. The image analyses were performed by using Image-Pro Plus 6.0 software (6.0, Media Cybernetics Inc., Rockville, MD, USA). Image-Pro Plus is designed for processing, enhancing and 
analyzing pictures; it has exceptionally rich measurement and customization features. In the present trials, 15 large fields of view $(5000 \times)$ and 15 small fields of view $(10,000 \times)$ of the SEM micrographs were randomly selected in order to analyze the average diameter, the distribution, and quantity of the annealed carbides of the test steels with different additions of RE. Similarly, 15 large fields of view $(100 \times)$ and 15 small fields of view $(200 \times)$ of the optical microscopys $(O M)$ were randomly selected in order to analyze the secondary dendrite arm spacing of the as-casted specimens and these statistics are based on reference [26]. In addition, the types of the annealed carbides were extensively analyzed by SEM equipped with energy dispersive X-ray spectroscopy (EDX).

The tempered carbides substructure of the test steels was observed using an X-ray diffraction (XRD) with $\mathrm{Cu}-\mathrm{K} \alpha(\lambda=1.5406 \AA)$ with a scanning angle from $15^{\circ}$ to $85^{\circ}$ and a scanning speed of $2^{\circ} / \mathrm{min}$ and a field-emission transmission electron microscope (TEM) operated at $200 \mathrm{kV}$. The TEM observation was conducted by using F20 (FEI company, Hillsboro, OR, USA), which is also equipped with an Oxford INCA type spectrometer (Japan Electronics Corporation, Tokyo, Japan) and GATAN 832 CCD image recorder (Japan Electronics Corporation, Tokyo, Japan). TEM samples were mechanically thinned to the thickness of approximately $50 \mu \mathrm{m}$ by SiC paper, then punched into disks of $3 \mathrm{~mm}$ in diameter and further thinned by twin-jet electro polishing, mixing in of $10 \mathrm{vol} \%$ perchloric acid ethanol solution at a voltage of $20 \mathrm{~V}$ and a temperature between $-30{ }^{\circ} \mathrm{C}$ and $-20{ }^{\circ} \mathrm{C}$.

The X-ray diffraction (XRD; Cu-K $\alpha ; \lambda=1.5406 \AA$; with a scanning angle from $15^{\circ}$ to $85^{\circ}$ and a scanning speed of $2^{\circ} / \mathrm{min}$ ) combined with Reference intensity ratio analysis (RIR) [27] and MDI Jade 6.5 software(6.5, Materials Data Inc., Livermore, CA, USA) were applied for the qualitative and quantitative phase analysis.

Round bar tensile specimens were prepared in the longitudinal direction with the gage length and diameter of $25 \mathrm{~mm}$ and $5 \mathrm{~mm}$, respectively. They were then tested at a strain rate of $0.5 \mathrm{~mm} / \mathrm{min}$ by using an AG-100KNG tensile machine from Shimadzu (Kyoto, Japan).At least three tensile tests for each testing condition are adopted here for the average value. The tensile properties were tested at room temperature.

\section{Results}

\subsection{Carbides Evolution}

\subsubsection{Influence of RE Addition on As-Cast Carbides}

Figure 1a,e,f shows the metallographic and SEM micrographs of the as-cast microstructure of unmodified test steel (ORE). The results show that most of the eutectic carbides distribute in net shape and are generally coarse, Energy dispersive spectrometer (EDS) analysis shows these are $(\mathrm{V}, \mathrm{Mo})_{x} \mathrm{C}_{y}$ (Figure 1g). In addition, the as-cast microstructures of modified test steels are shown in Figure $1 \mathrm{~b}-\mathrm{d}, \mathrm{h}-\mathrm{j}$. The structural difference between unmodified and modified test steels are that the dendritic spacings turn into fine structures and eutectic carbides are refining or even disappearing. The secondary dendrite arm spacing of the as-casted specimens are quantitatively analyzed, as shown in Figure 2. The results show that the spacing of secondary dendrite arm was decreased from $72 \mu \mathrm{m}$ to $25 \mu \mathrm{m}$ with different additions of RE. It indicates that RE has a role in refining the secondary dendrite arm and the precipitation of eutectic carbides. A similar refining of the precipitation of eutectic carbides with a certain amount of RE addition was also described by J. Hufenbach [15] and Fu [18]. 


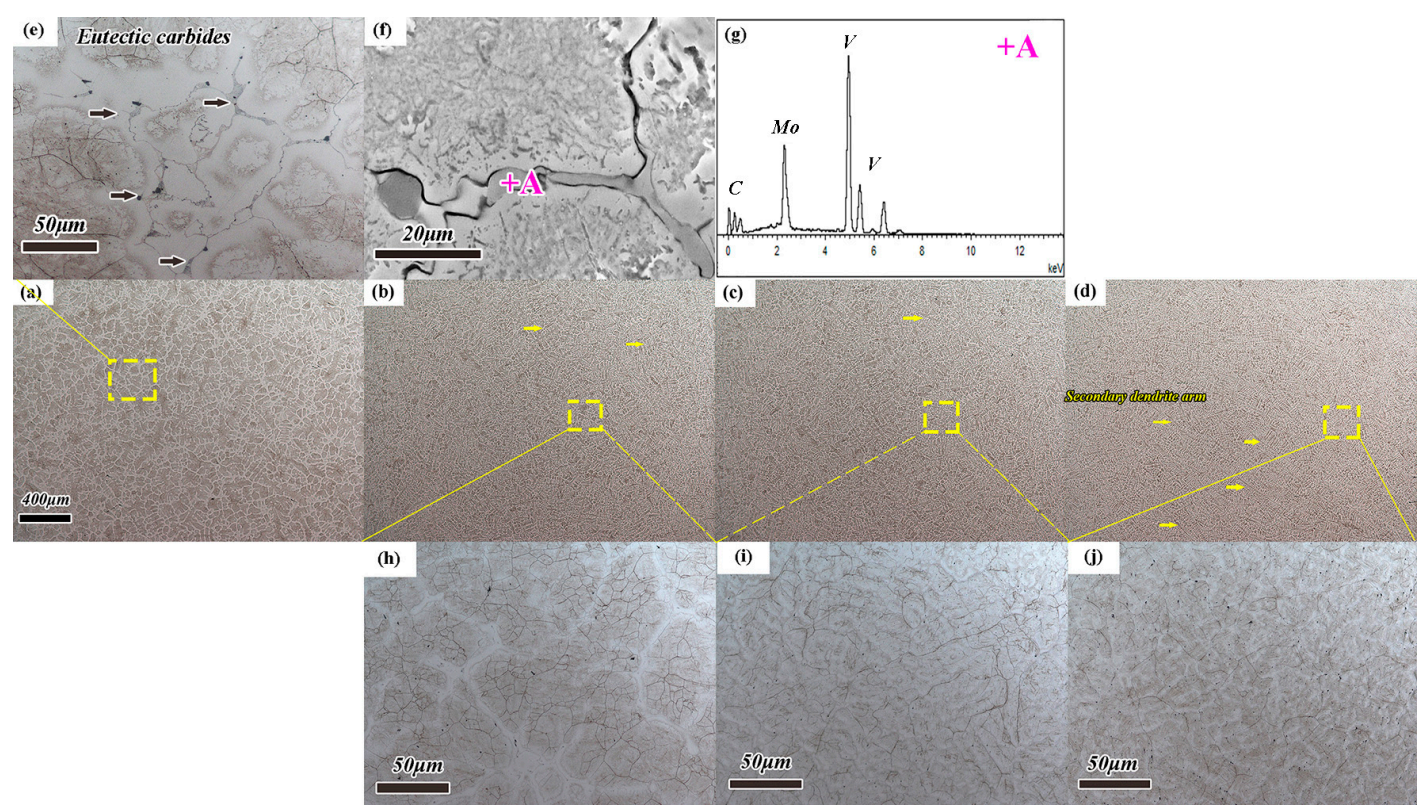

Figure 1. Metallographic and SEM micrographs of the specimens as-casted: (a) Metallographic observations in 0RE; (b) Metallographic observations in 0.018RE; (c) Metallographic observations in 0.048RE; (d) Metallographic observations in 0.15RE; (e) Metallographic observations in 0RE; (f) SEM micrographs in 0RE; (g) Energy dispersive spectrometer (EDS) analysis of eutectic carbides at A region in (f); (h) Metallographic observations in 0.018RE; (i) Metallographic observations in 0.048RE and (j) Metallographic observations in 0.15RE.

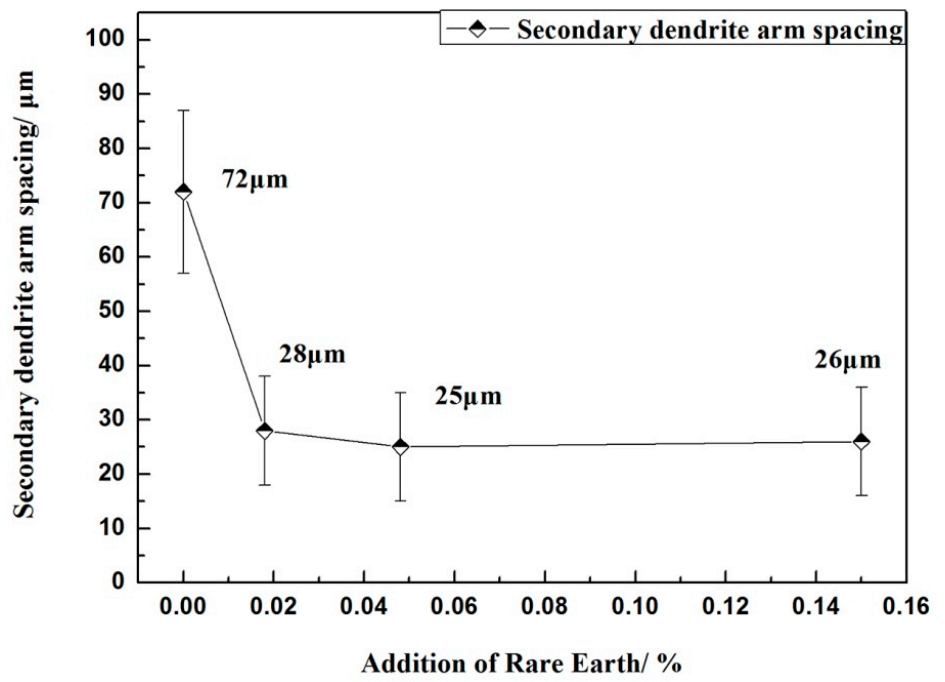

Figure 2. The secondary dendrite arm spacing of the specimens as-casted with different additions of RE.

\subsubsection{Influence of RE Addition on the Annealed Carbides}

The morphology of the annealed carbides in test steels was systematically investigated by metallographic and SEM micrographs, as shown in Figures 3 and 4 . The results show that the morphology of the annealed carbides gradually becomes ellipsoid and the chain carbides become less when adding the RE. Most notably, some large clusters of the annealed carbides are observed, as shown in Figure $4 \mathrm{a}, \mathrm{b}$ in the unmodified test steel (0RE). However, dispersion distributions of ellipsoid annealed carbides were observed in the observation field when adding RE (Figure 4d-f). In addition, coarse eutectic carbides are commonly found in the unmodified test steel (Figure $4 b, c)$, 
EDS analysis shows that these are $(\mathrm{V}, \mathrm{Mo})_{x} \mathrm{C}_{y}$. However, less coarse eutectic carbides are found in steel with RE addition (Figure $4 \mathrm{~d}-\mathrm{f}$ ).

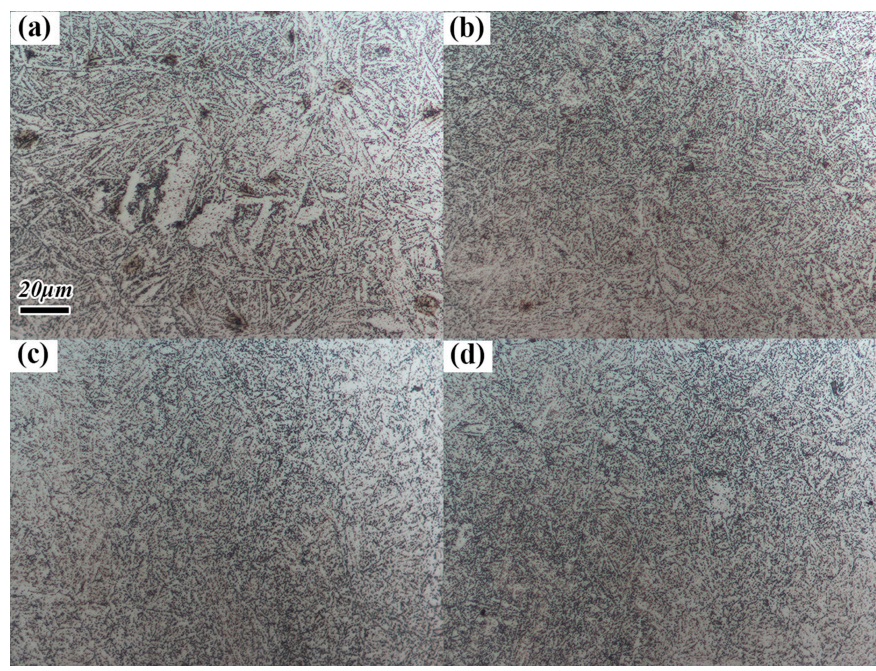

Figure 3. Metallographic observations of the annealed specimens: (a) 0RE; (b) 0.018RE; (c) 0.048RE and (d) 0.15RE.

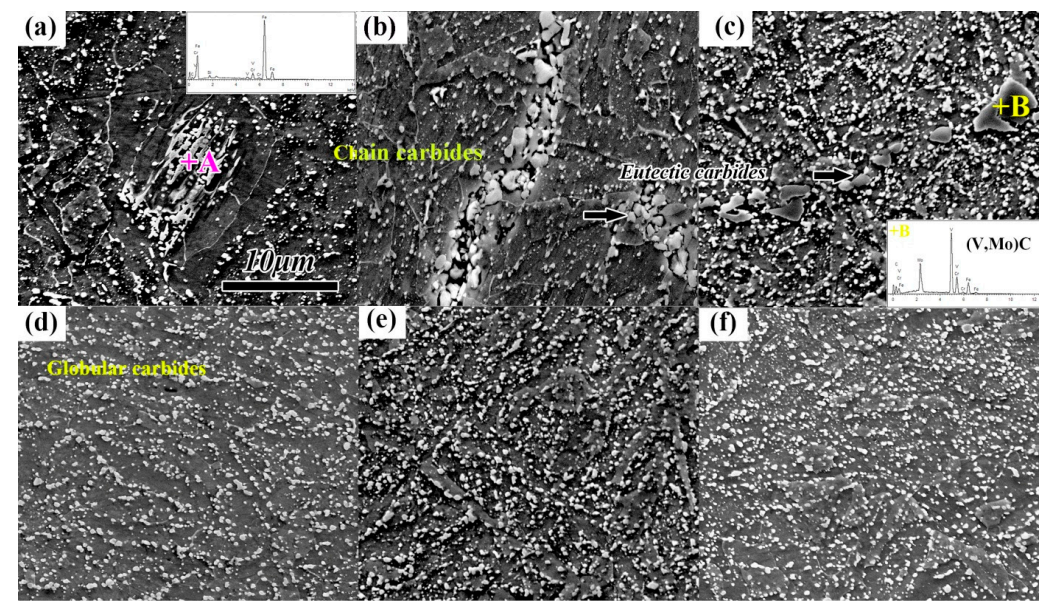

Figure 4. SEM and EDS observations of the annealed specimens: (a) Carbides aggregation in 0RE; (b) chain carbides in 0RE; (c) the eutectic carbides in 0RE; (d) ellipsoid carbides in 0.018RE; (e) ellipsoid carbides in 0.048RE and (f) ellipsoid carbides in 0.15RE. (The insert in (a) is the EDS analysis of carbides at $\mathrm{A}$ region, the insert in (c) is the EDS analysis of eutectic carbides at $\mathrm{B}$ region).

The relationship between the content of RE and the average diameter, the distribution, and quantity of the annealed carbides of the test steels are quantitatively analyzed, as shown in Figure 5. The results show that the average diameter of the annealed carbides almost unchanged with the increase of RE content, whereas the percentage is increased from $11.8 \%$ to $19.6 \%$ (Figure 5a). In addition, the annealed carbides distribution is discrete in the unmodified test steel (0RE), and the aggregate carbides with diameters greater than $1.5 \mu \mathrm{m}$ still account for more than $3 \%$ of the area fraction, as shown in Figure $5 \mathrm{~b}$. However, the size distribution of the annealed carbides is more uniform when RE is added, which indicates that RE has the role of spheroidizing and uniformly dispersing of the annealed carbides. In addition, the quantity of the annealed carbides increases from 1682 to 2078 in the same statistical region $\left(773.77 \mu \mathrm{m}^{2}\right)$ with the addition of 0.018 to $0.15 \mathrm{wt} \%$ RE (Figure $5 \mathrm{c}$ ). 

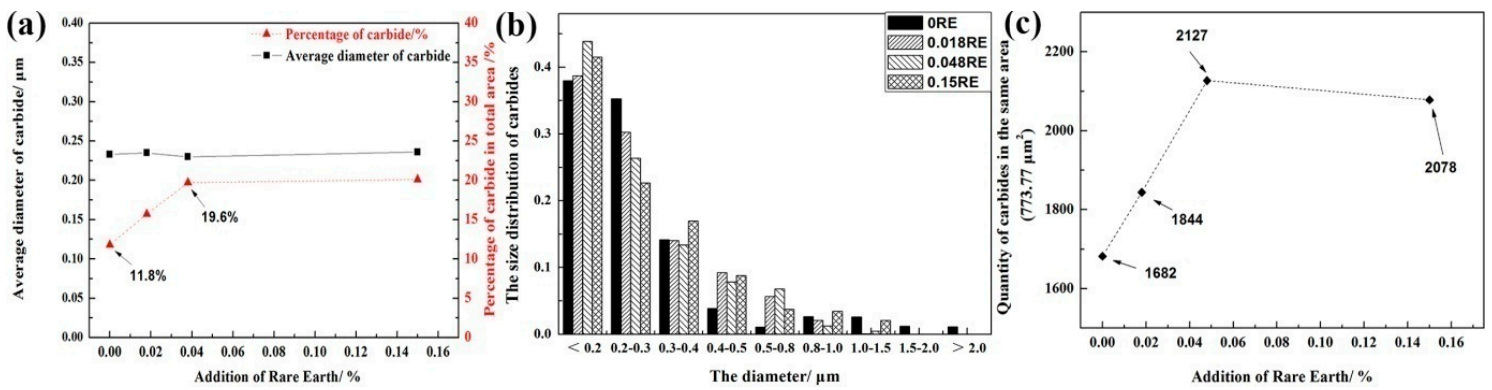

Figure 5. (a) Average diameter and percentage of the annealed carbides with different additions of RE; (b) The distributions of the annealed carbides with different additions of RE; and (c) The quantity of the annealed carbides in the same area $\left(773.77 \mu \mathrm{m}^{2}\right)$ with different additions of RE.

\subsubsection{Influence of RE Addition on the Tempered Carbides}

The quantitative analysis and crystal structure types of the tempered carbides of the test steels are examined by XRD. The corresponding patterns are shown in Figure 6 and the results are summarized in Table 2. The results show that the carbides of $M_{7} C_{3}, M_{8} C_{7}$ and $M_{23} C_{6}$ are detected in all test steels. In addition, the amount of the tempered $\mathrm{M}_{8} \mathrm{C}_{7}$ carbides slightly increases initially and then decreases with the alteration of RE addition from 0.018 to $0.15 \mathrm{wt} \%$. The effect of RE on the amount of the $\mathrm{M}_{8} \mathrm{C}_{7}$ carbides was also described by J. Hufenbach for high-strength Fe85Cr4Mo8V2C1 cast steel [15].

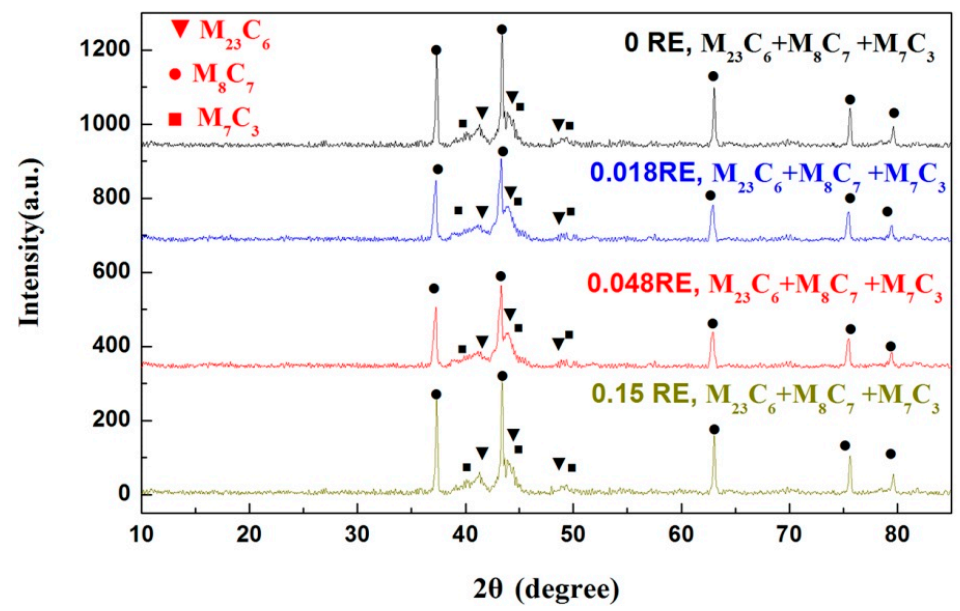

Figure 6. X-ray diffraction patterns of the 4Cr5MoSiV1-RE die steel with different additions of RE.

Table 2. Phase composition, space group and lattice parameters of carbides of the $4 \mathrm{Cr} 5 \mathrm{MoSiV} 1-x \mathrm{RE}$ $(x=0,0.018,0.048,0.15)$ steels determined by the analysis of XRD data.

\begin{tabular}{|c|c|c|c|c|c|c|}
\hline Steel & Structure Type & Space Group & $a(\mathrm{~nm})$ & $b(\mathrm{~nm})$ & $c(\mathrm{~nm})$ & Phase Content (wt \%) \\
\hline \multirow{3}{*}{ ORE } & $\mathrm{V}_{8} \mathrm{C}_{7}$ & $\mathrm{P} 4332(212)$ & 8.340 & 8.340 & 8.340 & 40 \\
\hline & $\mathrm{M}_{23} \mathrm{C}_{6}$ & Fm-3m(225) & 10.660 & 10.660 & 10.660 & 29 \\
\hline & $\mathrm{M}_{7} \mathrm{C}_{3}$ & $\operatorname{Pmcm}(51)$ & 7.015 & 12.153 & 4.532 & 31 \\
\hline \multirow{3}{*}{$0.018 R E$} & $\mathrm{~V}_{8} \mathrm{C}_{7}$ & P4332(212) & 8.340 & 8.340 & 8.340 & 48 \\
\hline & $\mathrm{M}_{23} \mathrm{C}_{6}$ & $\mathrm{Fm}-3 \mathrm{~m}(225)$ & 10.660 & 10.660 & 10.660 & 36 \\
\hline & $\mathrm{M}_{7} \mathrm{C}_{3}$ & $\operatorname{Pmcm}(51)$ & 7.015 & 12.153 & 4.532 & 16 \\
\hline \multirow{3}{*}{$0.048 \mathrm{RE}$} & $\mathrm{V}_{8} \mathrm{C}_{7}$ & P4332(212) & 8.340 & 8.340 & 8.340 & 52 \\
\hline & $\mathrm{M}_{23} \mathrm{C}_{6}$ & $\mathrm{Fm}-3 \mathrm{~m}(225)$ & 10.660 & 10.660 & 10.660 & 36 \\
\hline & $\mathrm{M}_{7} \mathrm{C}_{3}$ & $\operatorname{Pmcm}(51)$ & 7.015 & 12.153 & 4.532 & 12 \\
\hline \multirow{3}{*}{$0.15 \mathrm{RE}$} & $\mathrm{V}_{8} \mathrm{C}_{7}$ & P4332(212) & 8.340 & 8.340 & 8.340 & 44 \\
\hline & $\mathrm{M}_{23} \mathrm{C}_{6}$ & $\mathrm{Fm}-3 \mathrm{~m}(225)$ & 10.660 & 10.660 & 10.660 & 28 \\
\hline & $\mathrm{M}_{7} \mathrm{C}_{3}$ & $\operatorname{Pmcm}(51)$ & 7.015 & 12.153 & 4.532 & 28 \\
\hline
\end{tabular}


Meanwhile, the tempered carbides in unmodified (ORE) and modified test steels (0.15RE) are observed using both TEM bright-field (BF) observation and selected area electron diffraction (SAED) pattern in order to investigate the crystal structure and chemical composition, as shown in Figure 7. The results show that the particle in Figure $7 \mathrm{~b}, \mathrm{c}$ is the $\mathrm{M}_{23} \mathrm{C}_{6}$ carbides with the face-centered cubic crystal structure. The larger irregular block $\mathrm{M}_{23} \mathrm{C}_{6}$ carbides will be precipitated along the grain and subgrain boundaries when the tempering temperature is above $500{ }^{\circ} \mathrm{C}$ [28]. Further, a large spherical particle in Figure $7 \mathrm{a}, \mathrm{d}$ is identified to be the $\mathrm{M}_{7} \mathrm{C}_{3}$ carbides with the hexagonal close-packed crystal structure. Finally, a large number of small spherical particles in Figure 7a-c were identified to be the $\mathrm{M}_{8} \mathrm{C}_{7}$ carbides. In addition, from EDS analysis, it is known that these carbides are complex mixed carbides, whereby the $\mathrm{M}$ represents $\mathrm{Cr}, \mathrm{V}, \mathrm{Mn}, \mathrm{Mo}$ and Fe in unmodified steel (Figure 7e). However, when $\mathrm{RE}$ reaches $0.15 \mathrm{wt} \%$, the chemical compositions are changed to $\mathrm{Cr}, \mathrm{V}, \mathrm{Mn}, \mathrm{Mo}, \mathrm{Fe}, \mathrm{La}$ and $\mathrm{Ce}$ (Figure 7f). It shows that RE mainly influences the volumetric fraction and chemical composition of the tempered carbides, which has little influence on the crystal structure.

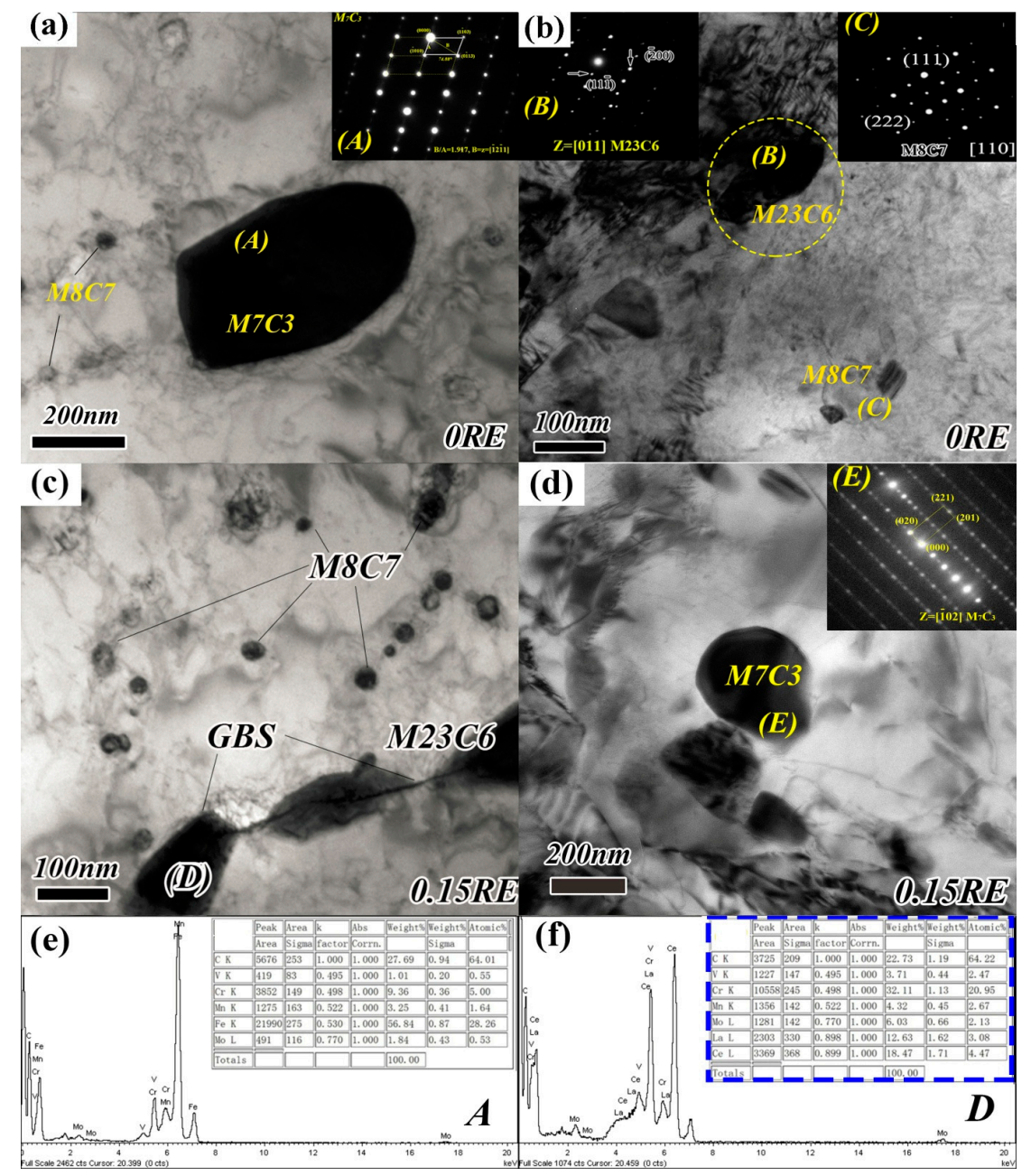

Figure 7. TEM microstructure with EDS analysis and diffraction pattern analysis of the types of carbides in the 4Cr5MoSiV1-RE die steel in 0RE and 0.15RE: (a) $M_{7} C_{3}$ and $M_{8} C_{7}$ in 0RE; (b) $M_{23} C_{6}$ and $\mathrm{M}_{8} \mathrm{C}_{7}$ in 0RE; (c) $\mathrm{M}_{23} \mathrm{C}_{6}$ and $\mathrm{M}_{8} \mathrm{C}_{7}$ in 0.15RE; (d) $\mathrm{M}_{7} \mathrm{C}_{3}$ in 0.15RE; (e) the EDS analysis of $\mathrm{M}_{7} \mathrm{C}_{3}$ at A region in (a) and (f) the EDS analysis of $\mathrm{M}_{23} \mathrm{C}_{6}$ at D region in (c). (The insert in (a) is the selected area electron diffraction (SAED) pattern of $\mathrm{M}_{7} \mathrm{C}_{3}$ at A region), (The insert in (b) is the SAED pattern of $\mathrm{M}_{23} \mathrm{C}_{6}$ at $\mathrm{B}$ region), (The insert in (b) is the SAED pattern of $\mathrm{M}_{8} \mathrm{C}_{7}$ at $\mathrm{C}$ region), and (the insert in (d) is the SAED pattern of $M_{7} C_{3}$ at $E$ region). 
In summary, adding RE leads to a refining of eutectic structure and coarse eutectic carbides. In addition, the morphology of the annealed carbides initiates changes from strip shape to ellipsoidal shape, and the amount of the tempered $\mathrm{M}_{8} \mathrm{C}_{7}$ carbides increases initially and then decreases with the alteration of RE addition from 0.018 to $0.15 \mathrm{wt} \%$.

\subsection{Tensile Property}

Table 3 presents the yield strength (YS), ultimate tensile strength (UTS), elongation and reduction of area of each sample of $4 \mathrm{Cr} 5 \mathrm{MoSiV} 1$ steels with different addition of RE. The average value of yield strength (YS) and ultimate tensile strength (UTS) slightly increases from $1227 \mathrm{MPa}$ to $1254 \mathrm{MPa}$ and $1452 \mathrm{MPa}$ to $1474 \mathrm{MPa}$ when the content of RE is $0.048 \mathrm{wt} \%$. However, when the RE content reaches $0.15 \mathrm{wt} \%$, the average value of yield strength (YS) and ultimate tensile strength (UTS) decreases to $1213 \mathrm{MPa}$ and $1430 \mathrm{MPa}$, respectively. A similar decrease of the tensile strength after reaching a certain amount of RE addition was also described by J. Hufenbach [15] and Wang [25]. In addition, Figure 8 shows the engineering stress-strain curves of the four specimens. The results show that all four test steels exhibit a similar tensile response, the elongation rate of $0.048 \mathrm{RE}$ steel increases slightly to $15 \%$, higher than $12 \%$ for the 0 RE steel.

Table 3. Variation in tensile strength of each sample in response to different additions of RE.

\begin{tabular}{|c|c|c|c|c|c|c|c|c|c|}
\hline \multirow[t]{2}{*}{ Alloy } & \multirow[t]{2}{*}{ No. } & \multicolumn{2}{|c|}{$\begin{array}{l}\text { Yield Strength }(\mathrm{YS}) \\
\left(\sigma_{0.2}\right)(\mathrm{Mpa})\end{array}$} & \multicolumn{2}{|c|}{$\begin{array}{l}\text { Ultimate Tensile Strength } \\
\text { (UTS) }\left(\sigma_{\mathrm{b}}\right)(\mathrm{Mpa})\end{array}$} & \multicolumn{2}{|c|}{ Elongation Rate ( $\delta$ ) } & \multicolumn{2}{|c|}{ Reduction of Area $(\psi)$} \\
\hline & & Vaule & Average Vaule & Vaule & Average Vaule & Vaule & Average Vaule & Vaule & Average Vaule \\
\hline \multirow{3}{*}{ ORE } & $1 \#$ & 1228 & \multirow{3}{*}{1227} & 1453 & \multirow{3}{*}{1452} & 12.5 & & 48 & \multirow{3}{*}{48} \\
\hline & 2\# & 1228 & & 1455 & & 12 & 12 & 47.5 & \\
\hline & $3 \#$ & 1225 & & 1448 & & 13 & & 48.5 & \\
\hline \multirow{3}{*}{ 0.018RE } & $1 \#$ & 1238 & \multirow{3}{*}{1236} & 1465 & \multirow{3}{*}{1461} & 13 & & 50 & \multirow{3}{*}{48.5} \\
\hline & 2\# & 1235 & & 1458 & & 13 & 13 & 48 & \\
\hline & $3 \#$ & 1235 & & 1460 & & 13 & & 48 & \\
\hline \multirow{3}{*}{ 0.048RE } & $1 \#$ & 1257 & \multirow{3}{*}{1254} & 1478 & \multirow{3}{*}{1474} & 16.5 & & 54.5 & \multirow{3}{*}{53} \\
\hline & 2\# & 1250 & & 1470 & & 14 & 15 & 51 & \\
\hline & $3 \#$ & 1255 & & 1474 & & 14.5 & & 53.5 & \\
\hline \multirow{3}{*}{$0.15 R E$} & $1 \#$ & 1210 & \multirow{3}{*}{1213} & 1425 & \multirow{3}{*}{1430} & 13.5 & & 50 & \multirow{3}{*}{50} \\
\hline & 2\# & 1212 & & 1430 & & 14 & 13.5 & 49 & \\
\hline & 3\# & 1217 & & 1435 & & 13 & & 51 & \\
\hline
\end{tabular}

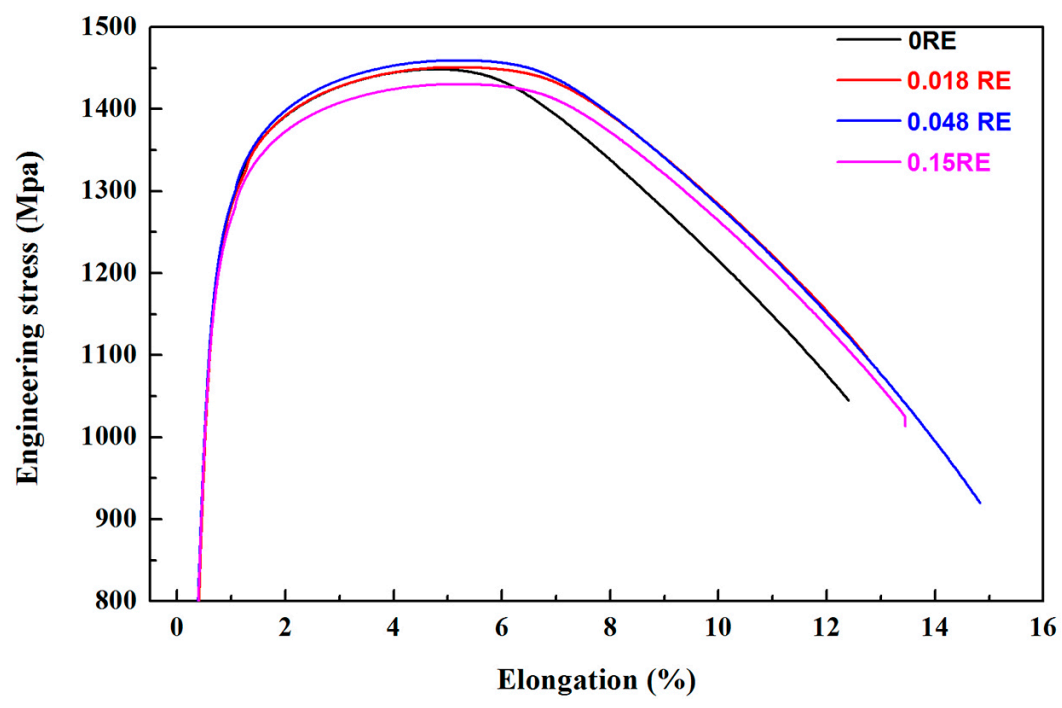

Figure 8. The representative engineering tensile stress-strain curves in response to different additions of RE. 


\section{Discussion}

\subsection{Carbides Evolution Induced by RE Addition}

The reasons for the refinement of eutectic carbides with different addition of RE can be summarized as follows: on the one hand, the solubility of RE in the matrix is very small, and most of the RE in steel will be obviously segregated and enriched into the front of dendrites during the solidification process, and leading to high composition supercooling [29]. This is advantageous to the decrease of dendrite spacing. Therefore, the dendrite structure and the eutectic carbides formed in the residual melts at the end of the solidification process were refined (Figures 1 and 2). On the other hand, according to the heterogeneous nucleation theory proposed by Turnbull [30], whether the additive contributes to nucleation of molten metal depends on the following two conditions. First, the additive must remain at the melting point above the solid phase when the substrate is nucleated. Second, the index of the lattice surface of the substrate phase and the matrix should be less mismatched. The low mismatching, smaller surface energy, leads to a decrease of super-cooling required for nucleation, and results in refining of the grains. RE-inclusion possesses both high melting point and low mismatching between the matrix through the preliminary research work on the influence of RE on inclusions in 4Cr5MoSiV1 die steel by our group [19]. Moreover, the most common form of inclusions are found believed to be $\mathrm{RE}$ oxy-sulfides $\left(\mathrm{Ce}_{2} \mathrm{O}_{2} \mathrm{~S}\right)$ with various $\mathrm{RE}$ contents $(0,0.015,0.025$ and $0.10 \mathrm{wt} \%)$ in $4 \mathrm{Cr} 5 \mathrm{MoSiV} 1$ die steel [19]. In addition, the lattice disregistry between (0001) $\mathrm{Ce}_{2} \mathrm{O}_{2} \mathrm{~S}$ and (111) $\delta$-Fe was only 3.5\% [19]. Simultaneously, Bramfitt [31] has shown that the additive is effective heterogeneous nuclei if the lattice misfit between the inclusions and the matrix is less than $6 \%$. Therefore, RE-inclusion like $\mathrm{Ce}_{2} \mathrm{O}_{2} \mathrm{~S}$ can be used as inoculants to greatly enhance nucleation, which is advantageous to the development of dendritic crystals to polycrystals and reduces dendrite spacing [18]. During the process of austenite growth, the dendritic crystals contact with each other to form a framework, which hinders the continuous growth of eutectic carbides [32]. In addition, the reason for the coarse ellipsoid eutectic carbides was commonly found after annealing in ORE samples as the carbides dissolved progressively into matrix when the heat treatment temperature increased. The sharp corners of the carbides became more round and some vulnerable areas began to crack.

In addition, the evolution of the annealed carbides from chain forms to ellipsoid forms are explained in that not only the solubility of RE in steel is very limited but also the RE atoms tend to segregate on carbides/matrix interfaces during the heat treatment process. In addition, the much larger atomic radius of RE, $0.3745 \mathrm{~nm}$ and $0.3637 \mathrm{~nm}$ for La and Ce, respectively, than that of Fe $(0.254 \mathrm{~nm})$ will cause lattice distortion and thus decreasing carbides stability. As a result, the preferred growth rate of the annealed carbides is hindered, thereby preventing the formation of the chain carbides [33].

In order to accurately investigate the effect of $\mathrm{RE}$ on the amount of $\mathrm{V}_{8} \mathrm{C}_{7}$-type carbides precipitation, it is necessary to quantify the relationship between the amount of RE in the steel and the solution temperature of $\mathrm{V}_{8} \mathrm{C}_{7}$-type carbides. To date, a large number of experimental results showed that $\mathrm{V}_{x} \mathrm{C}_{y}$-type carbides had a certain degree of carbon atom vacancy, so the chemical formulas of $\mathrm{V}_{x} \mathrm{C}_{y}$-type carbides were generally $\mathrm{VC}_{0.75}, \mathrm{VC}_{0.875}$ and $\mathrm{VC}$ and so on. In this part, we assume that the possibility of $\mathrm{V}_{x} \mathrm{C}_{y}$-type carbides in steel is the absence of interstitial atoms. The formula of the equilibrium solid solubility of VC-type carbides in steel is shown in Formula (1) [34]:

$$
\lg \{[\mathrm{V}] \cdot[\mathrm{C}]\}=6.72-\frac{9500}{T},
$$

In addition, the activity coefficients of the RE and other solute elements in steel on $\mathrm{V}$ and $\mathrm{C}$ elements were derived into the Formula (1), and the solubility product of VC-type carbides with RE and without RE experimental steels was calculated. Table 4 shows the interaction coefficient $e_{i}^{j}$ of various elements in liquid steel at $1873 \mathrm{~K}$ from Wagner's relation [35,36]. In addition, the formula of solid solubility of binary second phases MC-type carbide in steel is Formula (2) [37]: 


$$
\lg \{[\mathrm{M}] \cdot[\mathrm{C}]\}=A-\frac{B}{T}-\sum_{j=1}^{n} \frac{A_{\mathrm{Fe}}}{100 A_{j} \ln 10} e_{M}^{j} w_{j}-\sum_{j=1}^{n} \frac{A_{\mathrm{Fe}}}{100 A_{j} \ln 10} e_{C}^{j} w_{j}
$$

where $[\mathrm{M}],[\mathrm{C}]$ is the mass fractions of $\mathrm{M}$ and $\mathrm{C}$ elements, which are solid soluble in steel, respectively. $A$ and $B$ are constants, where $A$ is $6.72, B$ is $9500, A_{j}$ for atomic weight, and $w_{j}$ for mass fraction in steel. According to the chemical composition of experimental steels in Table 1, the solid solubility product of VC-type carbides in the unmodified test steel (ORE) is calculated by using the Formula (3):

$$
\begin{aligned}
& \lg \{[\mathrm{V}] \cdot[\mathrm{C}]\}=6.72-\frac{9500}{T_{56}}-\frac{56}{100 \times 12 \times \ln 10} e_{\mathrm{C}}^{\mathrm{C}} w_{\mathrm{C}}-\frac{56}{100 \times 28 \times \ln 10} e_{\mathrm{C}}^{\mathrm{Si}} w_{\mathrm{Si}}-\frac{56}{100 \times 55 \times \ln 10} e_{\mathrm{C}}^{\mathrm{Mn}} w_{\mathrm{Mn}} \\
& -\frac{56}{100 \times 52 \times \ln 10} e_{\mathrm{C}}^{\mathrm{Cr}} w_{\mathrm{Cr}}-\frac{56}{100 \times 51 \times \ln 10} e_{\mathrm{C}}^{\mathrm{V}} w_{\mathrm{V}}-\frac{56}{100 \times 96_{56} \times \ln 10} e_{\mathrm{C}}^{\mathrm{Mo}} w_{\mathrm{Mo}} \\
& -\frac{56}{100 \times \frac{140}{56} \times \ln 10} e_{\mathrm{C}}^{\mathrm{C}} w_{\mathrm{Ce}}-\frac{56}{100 \times 12 \times \ln 10} e_{\mathrm{V}}^{\mathrm{C}} w_{\mathrm{C}}-\frac{56}{100 \times 28 \times \ln 10} e_{\mathrm{V}}^{\mathrm{Si}} w_{\mathrm{Si}} \\
& -\frac{56}{100 \times 55 \times \ln 10} e_{\mathrm{V}}^{\mathrm{Mn}} w_{\mathrm{Mn}}-\frac{56}{100 \times 52 \times \ln 10} e_{\mathrm{V}}^{\mathrm{Cr}} w_{\mathrm{Cr}}-\frac{56}{100 \times 51 \times \ln 10} e_{\mathrm{V}}^{\mathrm{V}} w_{\mathrm{V}} \\
& -\frac{56}{100 \times 96 \times \ln 10} e_{\mathrm{V}}^{\mathrm{Mo}} w_{\mathrm{Mo}}-\frac{56}{100 \times 140 \times \ln 10} e_{\mathrm{V}}^{\mathrm{Ce}} w_{\mathrm{Ce}} \\
& =6.582951-\frac{9187.7954}{T}
\end{aligned}
$$

Similarly, the solid solubility product of VC-type carbides in steel in 0.018RE, 0.048RE and 0.15RE experimental steels are as follows (4)-(6):

$$
\begin{gathered}
\lg \{[\mathrm{V}] \cdot[\mathrm{C}]\}=6.582731-\frac{9186.3783}{T}, \\
\lg \{[\mathrm{V}] \cdot[\mathrm{C}]\}=6.58071-\frac{9172.5043}{T}, \\
\lg \{[\mathrm{V}] \cdot[\mathrm{C}]\}=6.57911-\frac{9174.6018}{T}
\end{gathered}
$$

Further, the total solution temperature of VC-type carbides in steel can be calculated by the following Formula (7) [36].

$$
T_{\mathrm{AS}}=\frac{B}{A-\lg \left(M \cdot X^{x}\right)},
$$

In Formula (7), the constants $A$ and $B$ are the same as in Formula (3), $M$ and $X$ are the mass fractions of the second phase (VC-type carbide) in steel, respectively (\%), and the total solution temperature of VC-type carbide in ORE steel can be calculated by Formula (7), and the results are as shown below:

$$
T_{\mathrm{AS}}=\frac{9187.7954}{6.582951-\lg (0.37 \times 1.05)}=1313.750855129 \mathrm{~K},
$$

Similarly, the total solution temperature of VC-type carbide in 0.018RE, 0.048RE and 0.15RE steel is $1308 \mathrm{~K}, 1306 \mathrm{~K}$ and $1310 \mathrm{~K}$, respectively. The calculation results show that the addition of RE elements in steel can promote the dissolution of $\mathrm{V}$ and reduce the total solution temperature of VC-type carbides significantly and the maximum temperature difference can be $7 \mathrm{~K}$ ( $1313 \mathrm{~K}$ to $1306 \mathrm{~K}$ ). After tempering at the same temperature, the saturated $\mathrm{V}$ element in the matrix will be dispersed in the form of VC-type carbide precipitation, and the strength of the steel can be improved to a certain extent.

Table 4. Interaction coefficient $e_{i}^{j}$ of various elements in liquid steel at $1873 \mathrm{~K}$.

\begin{tabular}{cccccccc}
\hline Element $(\boldsymbol{i}, \boldsymbol{j})$ & $\mathbf{C}$ & $\mathbf{S i}$ & $\mathbf{M n}$ & $\mathbf{C r}$ & $\mathbf{V}$ & Mo & Ce \\
\hline $\mathrm{V}$ & -3.4 & 4.2 & 0 & 0 & 1.3 & 0 & $-2836 / \mathrm{T}+1.40$ \\
$\mathrm{C}$ & $8890 / \mathrm{T}$ & $4.84+7370 / \mathrm{T}$ & $-5070 / \mathrm{T}$ & $7.02-21,800 / \mathrm{T}$ & $23,900 / \mathrm{T}-22.9$ & $3.86-17,870 / \mathrm{T}$ & $-150 / \mathrm{T}+0.05$ \\
\hline
\end{tabular}




\subsection{Tensile Property Induced by RE Addition}

The dimensions, morphology and volumetric fraction of carbides play a critical role in improving the strength properties of $4 \mathrm{Cr} 5 \mathrm{MoSiV} 1$ die steel. In this study, the main reasons for the increase in strength properties from the aspect of carbides evolution can be summarized as follows: first, the proeutectoid carbides not only influence the uniformity of microstructure, but also have a very significant influence on the strength properties [38]. The cracks tend to grow and spread around chain proeutectoid carbides [37]. Second, the effect of eutectic carbides modification by adding RE results in the finer morphologies observed in Figure 1. Hence, more carbon and other alloy elements dissolve into matrix at the high-temperature austenitizing treatment, and enhance the precipitation of alloy carbides during tempering. However, a further increase of the RE content to $0.15 \mathrm{wt} \%$ results in a slightly decrease of yield and ultimate strength. The trend partly can be explained by the changing phase fractions which are described above (Table 2). The fraction of the tempered $\mathrm{M}_{8} \mathrm{C}_{7}$ carbides increased from 40 to $52 \mathrm{wt} \%$ by adding $0.048 \mathrm{wt} \% \mathrm{RE}$ in the test steels. Further additions of RE $(0.15 \mathrm{wt} \%)$ led to a significant decrease of the tempered $\mathrm{M}_{8} \mathrm{C}_{7}$ carbides fraction from 52 to $44 \mathrm{wt} \%$. As a kind of nano-carbides, $\mathrm{M}_{8} \mathrm{C}_{7}$ carbides have the function of improving precipitation strengthening according to research proposed by Hojun Gwon [39] and J. Hufenbach [15]. In addition, the ductility was better with various RE contents $(0,0.018,0.048$ and 0.15 wt \%) addition (Table 3). One possible explanation for the observed enhanced ductility of the RE addition may be found in the arrangement of the carbides [15]. The complex chain carbides became increasingly interrupted with the RE addition; therefore, crack propagation along this path was hampered $[40,41]$.

\section{Conclusions}

In this study, the influence of RE additions $(0,0.018,0.048$ and $0.15 \mathrm{wt} \%)$ on the carbides evolution and tensile property of $4 \mathrm{Cr} 5 \mathrm{MoSiV} 1-\mathrm{RE}$ die steel were investigated. The main results are summarized as follows:

1. The microstructure observation of as-cast shows that after adding RE, it will lead to a refining of eutectic structure and coarse eutectic carbides.

2. The morphology of the annealed carbides initiates changes from strip shape to ellipsoidal shape, and the quantity of the annealed carbides increases from 1682 to 2078 in the same statistical region $\left(773.77 \mu \mathrm{m}^{2}\right)$ with the alteration of $\mathrm{RE}$ addition from 0.018 to $0.15 \mathrm{wt} \%$.

3. The amount of the tempered $\mathrm{M}_{8} \mathrm{C}_{7}$ carbides increases initially and then decreases with the alteration of RE addition from 0.018 to $0.15 \mathrm{wt} \%$. The addition of RE influences the chemical composition and morphology of tempered carbides, which has little influence on the lattice structure.

4. Tensile test shows that ultimate tensile strength (UTS) and elongation rate of 0.048RE steel increases slightly to $1474 \mathrm{MPa}$ and $15 \%$, higher than the $1452 \mathrm{MPa}$ and $12 \%$ for the unmodified test steel (0RE), respectively.

5. Adding 0.048 wt \% RE content to the $4 \mathrm{Cr} 5 \mathrm{MoSiV} 1$ die steel can obtain tool steels with better tensile strength and elongation rate, which is promising for advanced tool design.

Acknowledgments: The authors acknowledge the financial support by the National Key Research and Development Program of China (2016YFB0300401). This work also was supported by the Cooperation Program of Hubei province and Chinese Academy of Sciences (The Research and Development of Key Technologies for Special Steel of Homogeneous High Performance).

Author Contributions: Hanghang Liu carried out the experiments and analysis of the results. Paixian Fu, Hongwei Liu, Chen Sun and Jinzhu Gao prepared and revised the manuscript. Dianzhong Li contributed to the interpretation and discussion of results.

Conflicts of Interest: The authors declare no conflict of interest. 


\section{References}

1. Zhou, Q.C.; Wu, X.C.; Shi, N.N.; Li, J.; Min, N. Microstructure evolution and kinetic analysis of DM hot-work die steels during tempering. Mater. Sci. Eng. A 2011, 528, 5696-5700. [CrossRef]

2. Tsujii, N.; Abe, G.; Fukaura, K.; Sunada, H. High temperature low cycle fatigue behaviour of a $4.2 \mathrm{Cr}-2.5$ Mo-V-Nb hot work tool steel. J. Mater. Sci. Lett. 1996, 15, 1251-1254. [CrossRef]

3. Li, G.; Li, X.; Wu, J. Study of the thermal fatigue crack initial life of H13 and H21 steels. J. Mater. Process. Technol. 1998, 74, 23-26. [CrossRef]

4. Arif, A.; Sheikh, A.; Qamar, S. A study of die failure mechanisms in aluminum extrusion. J. Mater. Process. Technol. 2003, 134, 318-328. [CrossRef]

5. Telasang, G.; Majumdar, J.D.; Padmanabham, G.; Manna, I. Wear and corrosion behavior of laser surface engineered AISI H13 hot working tool steel. Surf. Coat. Technol. 2015, 261, 69-78. [CrossRef]

6. Wei, M.X.; Wang, S.Q.; Wang, L.; Cui, X.H.; Chen, K.M. Effect of tempering conditions on wear resistance in various wear mechanisms of H13 steel. Tribol. Int. 2011, 44, 898-905. [CrossRef]

7. Sola, R.; Giovanardi, R.; Parigi, G.; Veronesi, P. A novel method for fracture toughness evaluation of tool steel with post-tempering cryogenic treatment. Metals 2017, 7, 75. [CrossRef]

8. Perez, M.; Rodrigez, R.; Belzunce, F.J. The use of cryogenic treatment to increase the fracture toughness of the hot work tool steel used to make forging dies. Procedia Meteralia Sci. 2014, 3, 604-609. [CrossRef]

9. Poli, R.S.G.; Defanti, S.; Veronesi, P.; Parigi, G. Effect of deep cryogenic treatment on the properties of AISI M2 steel. In Proceedings of the European Conference on Heat Treatment and 22nd IFHTSE Congress, Venice, Italy, 20 May 2015.

10. Mebarki, N.; Delagnes, D.; Lamesle, P.; Delmas, F.; Levaillant, C. Relationship between microstructure and mechanical properties of a 5\% Cr tempered martensitic tool steel. Mater. Sci. Eng. A 2004, 387-389, 171-175. [CrossRef]

11. Kheirandish, S.; Noorian, A. Effect of niobium on microstructure of cast AISI H13 hot work tool steel. J. Iron Steel Res. Int. 2008, 15, 61-66. [CrossRef]

12. $\mathrm{Hu}, \mathrm{X} . ; \mathrm{Li}, \mathrm{L} . ; \mathrm{Wu}, \mathrm{X}$; Zhang, $\mathrm{M}$. Coarsening behavior of $\mathrm{M}_{23} \mathrm{C}_{6}$ carbides after ageing or thermal fatigue in AISI 4Cr5MoSiV1 steel with niobium. Int. J. Fatigue 2006, 28, 175-182. [CrossRef]

13. Ha, H.; Park, C.; Kwon, H. Effects of misch metal on the formation of non-metallic inclusions and the associated resistance to pitting corrosion in 25\% Cr duplex stainless steels. Scr. Mater. 2006, 55, 991-994. [CrossRef]

14. Cai, Y.C.; Liu, R.P.; Wei, Y.H.; Cheng, Z.G. Influence of Y on microstructures and mechanical properties of high strength steel weld metal. Mater. Des. 2014, 62, 83-90. [CrossRef]

15. Hufenbach, J.; Helth, A.; Lee, M.H.; Wendrock, H.; Giebeler, L.; Choe, C.Y.; Kim, K.H.; Kühn, U.; Kim, T.-S.; Eckert, J. Effect of cerium addition on microstructure and mechanical properties of high-strength Fe85Cr4Mo8V2C1 cast steel. Mater. Sci. Eng. A 2016, 674, 366-374. [CrossRef]

16. Kim, S.T.; Jeon, S.H.; Lee, I.S. Effects of rare earth metals addition on the resistance to pitting corrosion of super duplex stainless steel-Part 1. Corros. Sci. 2010, 52, 1897-1904. [CrossRef]

17. Ahn, J.H.; Jung, H.D.; Im, J.H.; Jung, K.H.; Moon, B.-M. Influence of the addition of gadolinium on the microstructure and mechanical properties of duplex stainless steel. Mater. Sci. Eng. A 2016, 658, 255-262. [CrossRef]

18. Fu, H.; Xiao, Q.; Li, Y. A study of the microstructures and properties of Fe-V-W-Mo alloy modified by rare earth. Mater. Sci. Eng. A 2005, 395, 281-287. [CrossRef]

19. Gao, J.; Fu, P.; Liu, H.; Fu, P.; Li, D. Effects of rare earth on the microstructure and impact toughness of H13 steel. Metals 2015, 5, 383-394. [CrossRef]

20. Liu, H.L.; Liu, C.J.; Jiang, M.F. Effect of rare earths on impact toughness of a low-carbon steel. Mater. Des. 2012, 33, 306-312. [CrossRef]

21. Sun, Z.; Zhang, C.S.; Yan, M.F. Microstructure and mechanical properties of M50NiL steel plasma nitrocarburized with and without rare earths addition. Mater. Des. 2014, 55, 128-136. [CrossRef]

22. Chen, L.; Ma, X.; Wang, L.; Ye, X. Effect of rare earth element yttrium addition on microstructures and properties of a $21 \mathrm{Cr}-11 \mathrm{Ni}$ austenitic heat-resistant stainless steel. Mater. Des. 2011, 32, 2206-2212. [CrossRef]

23. Jiang, X.; Song, S.H. Enhanced hot ductility of a Cr-Mo low alloy steel by rare earth cerium. Mater. Sci. Eng. A 2014, 613, 171-177. [CrossRef] 
24. Fu, H.; Xiao, Q. Effect of rare earth and titanium additions on the microstructures and properties of low carbon Fe-B cast steel. Mater. Sci. Eng. A 2007, 466, 160-165. [CrossRef]

25. Wang, M.; Mu, S.; Sun, F.; Wang, Y. Influence of rare earth elements on microstructure and mechanical properties of cast high-speed steel rolls. J. Rare Earth 2007, 25, 490-494. [CrossRef]

26. Ning, A.; Mao, W.; Chen, X.; Guo, H.; Guo, J. Precipitation behavior of carbides in H13 hot work die steel and its strengthening during tempering. Metals 2017, 7, 70. [CrossRef]

27. Hubbard, C.R.; Evans, E.H.; Smith, D.K. The reference intensity ratio, $I / I_{\mathrm{C}}$, for computer simulated powder patterns. J. Appl. Crystallogr. 1976, 9, 169-174. [CrossRef]

28. Dong, J.; Zhou, X.; Liu, Y.; Li, C.; Liu, C.; Guo, Q. Carbide precipitation in Nb-V-Ti microalloyed ultra-high strength steel during tempering. Mater. Sci. Eng. A 2017, 683, 215-226. [CrossRef]

29. $\mathrm{Xu}, \mathrm{Z} . \mathrm{M}$. Influence of $\mathrm{Ce}$ and $\mathrm{Al}$ on nodularization of eutectic in austenite-bainite steel. Mater. Res. Bull. 2000, 35, 1261-1268. [CrossRef]

30. Turnbull, D.; Vonnegut, B. Nucleation catalysis. Ind. Eng. Chem. 2002, 44, 1292-1298. [CrossRef]

31. Bramfitt, B.L. Planar lattice disregistry theory and its application on heterogistry nuclei of metal. Metall. Trans. 1970, 1, 1987-1995. [CrossRef]

32. Yang, Q.X.; Liao, B.; Liu, J.H.; Yao, M. Effect of rare earth elements on carbide morphology and phase transformation dynamics of high Ni-Cr alloy cast iron. J. Rare Earth 1998, 1, 37-41.

33. Xu, Y.W.; Song, S.H.; Wang, J.W. Effect of rare earth cerium on the creep properties of modified 9Cr-1Mo heat-resistant steel. Mater. Lett. 2015, 161, 616-619. [CrossRef]

34. Narita, K. Physical chemistry of the groups IVa (Ti, Zr), Va (V, Nb, Ta) and the rare earth elements in steel. Trans. ISIJ 1975, 15, 145-152.

35. Sharma, R.C.; Lakshmanan, V.K.; Kirkaldy, J.S. Solubility of niobium carbide and niobium carbonitride in alloyed austenite and ferrite. Metall. Mater. Trans. A 1984, 15, 545-553. [CrossRef]

36. Wang, L.M.; Du, T.; Lu, X.L.; Li, Z.B.; Gai, Y.C. Thermodynamics and application of rare earth elements in steel. J. Chin. RE Soc. 2013, 21, 251-254.

37. Long, Q.L. Second Phases in Structural Steels; Metallurgical Industry Press: Beijing, China, 2006; p. 119. (In Chinese)

38. Mudali, U.K.; Raj, B. High Nitrogen Steels and Stainless Steels-Manufacturing, Properties and Applications; Narosa Publishing House: New Delhi, India, 2004.

39. Gwon, H.; Kim, J.K.; Shin, S.; Cho, L.; de Cooman, B.C. The effect of vanadium micro-alloying on the microstructure and the tensile behavior of TWIP steel. Mater. Sci. Eng. A 2017, 696, 416-428. [CrossRef]

40. Wang, K.H.; Lee, S.; Lee, H. Effects of alloying elements on microstructure and fracture properties of cast high speed steel rolls: Part II. Fracture behavior. Mater. Sci. Eng. A 1998, 254, 296-304. [CrossRef]

41. Picasa, I.; Cuadrado, N.; Casellas, D.; Goez, A.; Llanes, L. Microstructural effects on the fatigue crack nucleation in cold work tool steels. Procedia Eng. 2010, 2, 1777-1785. [CrossRef] 